\title{
Primeiro registro do uso de Bromeliaceae por Elachistocleis ovalis (Schneider, 1799) (Anura: Microhylidae)
}

\author{
Edson Victor Euclides de Andrade ${ }^{1,4}$, Keitz Moura Albertim ${ }^{2}$ \& Geraldo Jorge Barbosa de Moura ${ }^{3}$ \\ ${ }^{1}$ Núcleo de Fauna-Centro de Triagem de Animais Silvestres, \\ Instituto Brasileiro do Meio Ambiente e dos Recursos Naturais Renováveis, \\ Superintendência no Estado de Pernambuco, \\ AV. 17 de agosto, CEP 52060-590, Recife, PE, Brasil \\ ${ }^{2}$ Departamento de Ciências Biológicas, Faculdade Frassinetti Do Recife, \\ Av. Conde da Boa Vista, CEP 50060-12, Recife, PE, Brasil \\ ${ }^{3}$ Núcleo de Biologia, Universidade Federal de Alagoas - UFAL, \\ AV. Manoel Severino Barbosa, s/n, Arapiraca, AL, Brasil \\ ${ }^{4}$ Autor para correspondência: Edson Victor Euclides de Andrade, edvieuan@ gmail.com.br
}

\begin{abstract}
ANDRADE, E.V.E., ALBERTIM, M. \& MOURA, G.J.B. First record of the use of bromeliads by Elachistocleis ovalis (Schneider, 1977) (Anura: Microhylidae). Biota Neotrop., 9(4): http://www.biotaneotropica.org.br/v9n4/ en/abstract?short-communication+bn01209042009.
\end{abstract}

Abstract: It is registered the use of terrestrial bromeliads by three individuals of Elachistocleis ovalis in an Atlantic Rainforest remnant of Northeastern Brazil. The animals occupied the axils of the leaves of the bromeliad base, the same individuals found inside the same axils more than once, during the day and at night. The species Elachistocleis ovalis is a ground dweller one and there's no previous record of using the bromeliads by this species. Apparently the axils serve not only as a diurnal shelter but also at night, at moments when the species is not in activity.

Keywords: bromeliads, diurnal shelter, new record, Amphibia.

ANDRADE, E.V.E., ALBERTIM, M. \& MOURA, G.J.B. Primeiro registro do uso de Bromeliaceae por Elachistocleis ovalis (Schneider, 1799) (Anura: Microhylidae). Biota Neotrop., 9(4): http://www.biotaneotropica. org.br/v9n4/en/abstract?short-communication+bn01209042009.

Resumo: Registra-se o uso de bromélias de solo por três indivíduos de Elachistocleis ovalis em um remanescente de Mata Atlântica do Nordeste Brasileiro. Os animais ocuparam as axilas das folhas de base, os mesmos indivíduos foram encontrados nas mesmas axilas mais de uma vez, no período diurno e no noturno. A espécie Elachistocleis ovalis é típica de solo, e não há registro anterior de uso de bromélias por esta espécie. Aparentemente a axila da bromélia serve como abrigo não apenas durante o dia, mas também à noite, nos momentos em que a espécie não estiver em atividade.

Palavras-chave: bromélias, abrigo diurno, novo registro, Amphibia. 


\section{Introdução}

Bromeliaceae constitui uma grande família composta, principalmente, de epífitas, a maioria delas apresentando ramos em roseta, formando um tanque central (Dejean \& Olmsted 1997). Para a Mata Atlântica de Pernambuco tem-se registro de 87 espécies de Bromeliaceae (Siqueira Filho 2003). No tanque central e nas axilas das folhas a água das chuvas se acumula, criando um micro-ambiente denominado fitotelmo (phytos = planta; telm = poça), que é ocupado por diferentes animais aquáticos (Maguire 1971), dentre eles os anuros (Lehtinen 2004).

Dentre os anuros são conhecidas 102 espécies que se reproduzem em fitotelmos (Lehtinen \& Nusball 2003). O tanque central e as axilas das bromélias, por acumularem água, representam micro-ambientes importantes como abrigo, alimentação e sítio de desova para algumas espécies de anuros (Peixoto 1995, Juncá \& Borges 2002, Lehtinen 2004), as quais utilizam as bromélias na maior parte da vida ou até mesmo durante todo o ciclo de vida, desenvolvendo estratégias avançadas relacionadas com o modo reprodutivo (Duellman 1985, Peixoto 1995, Haddad \& Prado 2005).

Elachistocleis ovalis (Schneider, 1799) é considerado um complexo de espécies (Lavilla et al. 2003) e apresenta ampla distribuição geográfica (Frost 2009). É considerada fossorial, semifossorial ou criptozóica (Kwet \& Di-bernardo 1999, Achaval \& Olmos 2003, Strusmann 2000), e não há; registro de utilização de bromélias em outros estudos (Juncá 2006, Junca \& Borges 2002, Peixoto 1995, Schneider \& Teixeira 2001, Schneider et al. 2001, Lehtinen 2004), constituindo esse o primeiro registro de uso desse microambiente pela espécie.

Esse estudo tem como objetivo registrar a ocorrência de E. ovalis em bromélias em remanescente de Mata Atlântica no nordeste do Brasil.

\section{Material e Metodos}

O estudo foi realizado na Estação Ecológica do Tapacurá - EET $\left(08^{\circ} 04^{\prime} \mathrm{S}\right.$ e $\left.35^{\circ} 12^{\prime} \mathrm{O}\right)$, situada a $50 \mathrm{~km}$ da cidade do Recife, no município de São Lourenço da Mata, Leste do Estado de Pernambuco, Brasil. A EET é atualmente administrada pela Universidade Federal Rural de Pernambuco e apresenta uma área total de aproximadamente 800 ha, circundada por monocultura da cana-de-açúcar, dos quais cerca de 400 ha representa áreas florestadas distribuídas em três fragmentos: Mata do Toró, Mata do Camucim e Mata do Alto da Buchada, e os outros 400 são correspondentes ao Lago Tapacurá, resultante do represamento do Rio Tapacurá, afluente do Rio Capibaribe.

A coleta foi realizada uma vez por semana durante dois períodos de 2008: de abril a junho (estação chuvosa) e de setembro a novembro (estação seca) e foi focada em bromélias de solo. As plantas eram primeiramente observadas, para registrar os animais que estivessem em área visível, e depois tinham suas folhas afastadas de modo a expor os animais que estivessem nas suas axilas. A estrutura da bromélia foi dividida em: 1) folhas do centro, correspondentes àquelas mais internas da roseta, geralmente mais jovens e eretas, formando as paredes do tanque central; 2) folhas da base, correspondentes àquelas que apresentam contato com o solo, ou às mais basais, acidentalmente acumulando água nas axilas; e 3) folhas do meio, correspondente às intermediárias, geralmente em número aproximado do dobro do número de folhas do centro e da base, geralmente acumulando água nas axilas.

Visando ao registro de possíveis recapturas, os animais foram individualizados pelos padrões de coloração dorsal e lateral.

\section{Resultados e Discussao}

Foram encontrados três indivíduos adultos de E. ovalis ocupando duas bromélias da espécie Portea leptantha (Harms), ambas localizadas na Mata do Alto da Buchada, apenas na estação seca. Uma das bromélias estava localizada em um grande afloramento rochoso ( $8^{\circ} 02$ ' 32.90" $\mathrm{S} \mathrm{e} 35^{\circ} 12^{\prime} 44^{\prime \prime} \mathrm{O}$ ), e apresentou um indivíduo na axila de uma folha da base (Figura 1a). Esse indivíduo foi avistado em duas noites (28/Setembro, 19:23 horas e 11/Novembro, 20:47 horas) e em uma manhã (1/Novembro, 9:12 horas) dentro da mesma bromélia. Em outra bromélia, localizada no centro da mata $\left(8^{\circ} 02^{\prime} 35.02\right.$ " $\mathrm{S}$ e $35^{\circ} 26^{\prime} 13$ " O), foram registrados dois indivíduos de E. ovalis em uma mesma axila (Figura 1b) Esses dois indivíduos foram vistos juntos em dois eventos consecutivos: uma à noite (1/Novembro, 21:10 h) e uma na manhã subseqüente (2/Novembro, 10:00 horas).

Elachistocleis ovalis caracteriza-se por ser tipicamente terrestre (Kwet \& Di-Bernardo 1999, Achaval \& Olmos 2003, Strusmann 2000) e reproduz em poças temporárias (Achaval \& Olmos 2003, Eterovick \& Sazima 2004, Thomé \& Brasileiro 2007, Toledo et al. 2003). A atividade reprodutiva de adultos de E. ovalis não foi registrada na
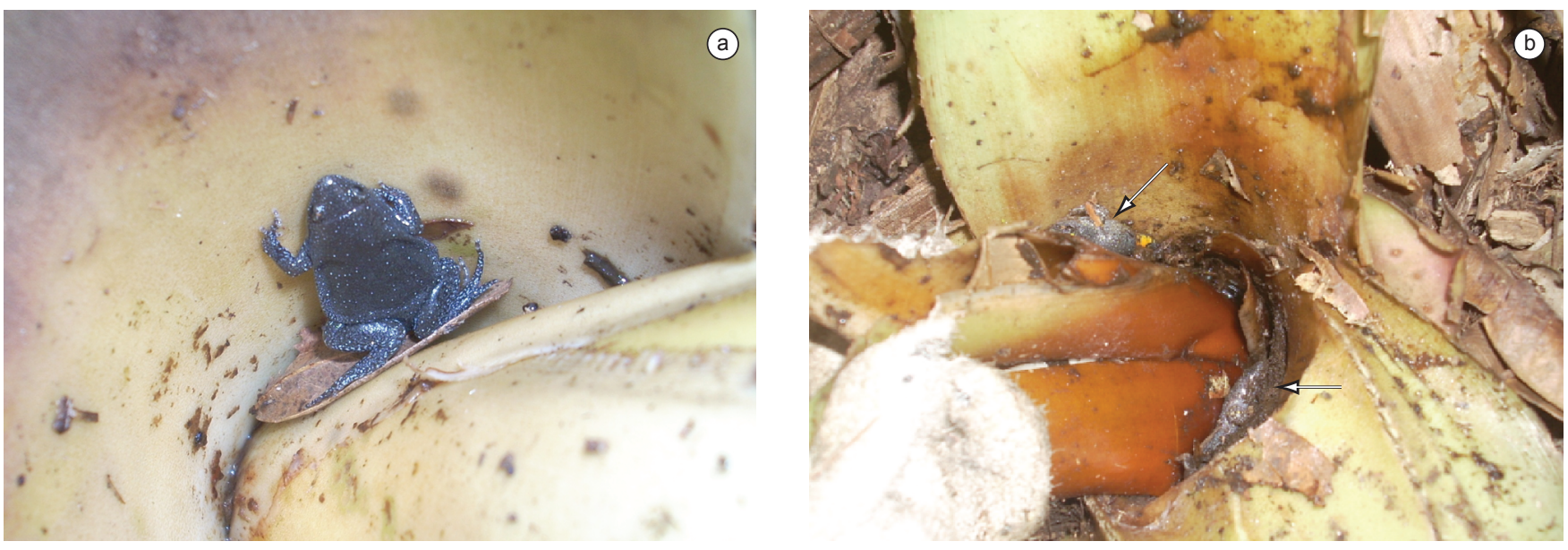

Figura 1. Indivíduos de Elachistocleis ovalis dentro de axila das folhas de base de duas bromélias (a e b) durante a estação seca, na Estação Ecológica do Tapacurá, Pernambuco.

Figure 1. Individuals of Elachistocleis ovalis inside the axil of the basement leaves of two bromeliads (a and b) during the dry season at Estação Ecológica do Tapacurá, Pernambuco. 
EET durante o período de estudo. No entanto alguns girinos foram registrados em poças temporárias. Nas bromélias, apenas adultos foram registrados. Assim, esse micro-ambiente parece estar sendo utilizado apenas como abrigo para os períodos não reprodutivos da população de E. ovalis na EET.

Investigações da fauna associada a bromélias podem revelar a utilização das mesmas por indivíduos de E. ovalis em outras regiões, bem como a freqüência e importância desta utilização.

\section{Agradecimentos}

A Lúcio Flausino Dias Júnior e a Íris Virgínia Cypriano de Melo e aos vigilantes da EET: Edriano Lima, Moacir Silva, Jailson Silva e Márcio José pela ajuda em campo. O trabalho foi licenciado pelo IBAMA (088/07-IBAMA/RAN).

\section{Referencias Bibliográficas}

ACHAVAL, F. \& OLMOS, A. 2003. Anfibios y reptiles del Uruguay. 2 ed. Graphis Impresora, Montevideo, Uruguay.

DEJEAN, A. \& OLMSTED, I. 1997. Ecological studies on Aechmea bracteata (Swartz) (Bromeliaceae). J. Nat. Hist. 31(9): 1313-1334.

DUELLMAN, W.E. 1985. Reproductive modes in anuran amphibians: phylogenetic significance of adaptive strategies. South African Jour. Scie. 81: 174-178.

ETEROVICK, P.C. \& SAZIMA, I. 2004. Anfíbios da Serra do Cipó -Minas Gerais Brasil. Amphibians from the Serra do Cipó. PUC Minas, Belo Horizonte.

FROST, D. 2009. Amphibians species of the world: an online reference. Version 3.0. (26 August, 2009). Electronic Database accessible at http:// research.amnh.org/herpetology/index.htm. American Museum of Natural History, New York, USA.

HADDAD, C.F.B. \& PRADO, C.P. 2005. Reproductive modes in Frogs and their unexpected diversity in the Atlantc Forest of Brazil. Bioscience. 55(3): 207-217.

JUNCÁ, F.A. \& BORGES, C.L.S. 2002. Fauna associada a bromélias terrícolas da Serra da Jibóia, Bahia. Sitientibus Série Ciênc. Biol. 2(1/2): 73-81.

JUNCÁ, F.A. 2006. Diversidade e uso de habitat por anfíbios anuros em duas localidades de Mata Atlântica, no norte do estado da Bahia. Biota Neotropica 6 (2): http://www.biotaneotropica.org.br/v6n2/pt/abstract?inv entory+bn03006022006 [Acesso em: 16 de novembro de 2008].
KWET, A \& DI-BERNARDO, M. 1999. Anfíbios. Amphibien. Amphibians. EDIPUCRS, Porto Alegre.

LAVILLA, E.O., VAIRA, M. \& FERRARI, L. 2003. A new species of Elachistocleis (Anura: Microhylidae) from the Andean Yungas of Argentina, with comments on the Elachistocleis ovalis-E. bicolor controversy. Amphibia-Reptilia 24: 269-284.

LEHTINEN, R.M. 2004. Ecology and Evolution of Phytotelm-breeding anurans. University of Michigan, Ohio. 73p.

LEHTINEN, R.M. \& NUSBALL, R.A. 2003. Parental care: a phylogenetic perspective. In Reproductive Biology and Phylogeny of the Anura (B.G.M. JAMIESON, ed). Ed. New Hampshire, Science Publishes Enfield, p.343-386.

MAGUIRE, B. 1971. Phytotelmata: Biota and Community Structure Determination in Plant-Held Waters. Annual Rev. of Ecol. and System. 2: 439-464.

PEIXOTO, O.L. 1995. Associação de anuros a bromeliáceas na mata Atlântica. Ver. da Univ. Rural, Série Ciên. da Vida, Seropédica. 17(12): 75-83.

SIQUEIRA FILHO, J.A. 2003. Fenologia da floração, ecologia da polinização e conservação de Bromeliaceae na Floresta Atlântica Nordestina. Tese de Doutorado, Universidade Federal de Pernambuco, Recife.

SCHNEIDER, J. A. P. \& TEIXEIRA, R. L. 2001. Relacionamento entre anfíbios anuros e bromélias da Restinga de Regência, Linhares, Espírito Santo, Brasil. Iheringia, Série Zool. 91: 41- 48.

SCHNEIDER, J. A. P., TEIXEIRA, R. L, AMMEIDA, G. I. 2001. Aspectos de Comunidades de Anfíbios bromelícolas em Região de mata Atlântica, do Espírito santo, Sudeste do Brasil. Rev. Nord. de Zool. 2(10): 57-62.

STRUSMANN, M. 2000. Herpetofauna. In Fauna silvestre da região do Rio Manso, MT. (C.R.J. ALHO, ed.). Brasília, p. 153-189.

THOMÉ, M.T.C. \& BRASILEIRO, C.A. 2007. Dimorfismo sexual, uso do ambinete e abundância sazonal de Elachistocleis cf. ovalis (Anura: Microhylidae) em um remanescente de Cerrado no Estado de São Paulo, Sudeste do Brasil. Biota Neot. 7(1): http://www.biotaneotropica.org.br/ v7n1/pt/abstract?article+bn00307012007.

TOLEDO, L.F., ZINA, J. \& HADDAD, C.F.B. 2003. Distribuição espacial e temporal de uma comunidade de anfíbios anuros do município de Rio Claro, São Paulo, Brasil. Holos Envir. 3(2): 136-149.

Recebido em 24/06/09 Versão reformulada recebida em 16/08/09 Publicado em 22/10/09 